\title{
El estudio académico de lo esotérico
}

\section{José Ricardo Chaves Pacheco}

Doctor en Literatura Comparada, Universidad Nacional Autónoma de México. Profesor e investigador en el Instituto de Investigaciones Filológicas de la Universidad Nacional Autónoma de México.

Correo electrónico: jrchavesp@aol.com

Fecha de recibido: 30 de marzo de 2015 - Fecha de aceptación: 25 de abril de 2015

\section{Palabras claves}

Esoterismo, esoteriología, estudio de las religiones, creencias, estudios de esoterismo occidental

\section{Keywords}

Esotericism, esoteriology, study of religions, beliefs, Study of the Western Esotericism

\begin{abstract}
Resumen
Este artículo se divide en dos partes. Primero, analiza el desarrollo lingüístico e histórico de los conceptos esotérico y esoterismo, proceso que evolucionó a una incipiente "conciencia histórica" entre los propios esoteristas, influenciada por el influjo historicista romántico, que conformó un nuevo tipo de esoterismo en tiempos de ciencia, democracia y modernidad. Y segundo, explica el proceso de transformación disciplinaria de los estudios de lo esotérico, el esoterismo y la esoterología hasta la imposición de la categoría académica de los "estudios de esoterismo occidental".
\end{abstract}

\begin{abstract}
This article is divided into two parts. First, it analyzes the linguistic and historical development of the esoteric and esotericism concepts, processes that evolved an incipient "historical consciousness" among the esotericists, influenced by the romantic historicist flow, which formed a new type of esotericism in times of science, democracy and modernity. Second, the article explains the process of disciplinary transformation of the study of esoterica, esotericism and esoterology until the imposition of the academic category of "Western Esotericism Studies".
\end{abstract}

En el último cuarto de siglo se ha dado un proceso cada vez más fuerte y estructurado en Estados Unidos y Europa de estudios académicos sobre "lo esotérico", con elaboraciones teóricas, metodológicas e históricas que buscan acercamientos serios a dicho ámbito, considerado hasta entonces indigno de la atención universitaria, por distintas razones y sinrazones. Esta nueva ola de estudios comienza a manifestarse en América Latina, un ámbito geográfico sin duda prolífico en posibilidades de investigación. El siguiente texto forma parte de una investigación más amplia que buscará abordar diversos tópicos esoterológicos desde la literatura en cuatro países del orbe panhispánico (España, México, Costa Rica y Argentina), a partir de las primeras décadas de funcionamiento del espiritismo y de la teosofía en dichos países (18901930).

\section{Esotérico y esoterismo. ¿Qué significan?}

Empecemos por definir esotérico y esoterismo, adjetivo y sustantivo. En su 
desarrollo lingüístico e histórico, primero fue el adjetivo y tiempo después vino el nombre, primero la cualidad y luego el objeto. De acuerdo con Pierre Riffard, durante mucho tiempo se atribuyó a Aristóteles el haber inventado dicho adjetivo, pero en realidad el que usó fue su antónimo, "exotérico". En su caso, lo opuesto a exotérico era lo "acromático", lo que se transmitía oralmente, de boca a oído, que es una de las características de lo esotérico, aunque este término no aparezca en él ${ }^{1}$. Quien utilizó el epíteto por vez primera fue Clemente de Alejandría, asociado con lo secreto, y en él sí como algo opuesto a lo exotérico, usando ambos términos en oposición complementaria; luego siguieron otros autores como el teúrgo neoplatónico Jámblico, que refiere lo esotérico a Pitágoras y su escuela, y el cristiano Orígenes, en tanto enseñanzas secretas reservadas para una élite.

En lengua inglesa, "esoteric" aparece en 1655, con Stanley para referirse a la escuela de Pitágoras; "esotery" en 1763, poco más de un siglo después; "esoterism" en 1835 y "esotericism" en 1846. En francés, el término "esotérisme" cristaliza hasta el siglo XIX, primero con Jacques Matter en 1828 y después con Pierre Leroux en 1840. No obstante estos usos pioneros, quien logró popularizar el término e incluso introducirlo como neologismo en otras lenguas fue el ocultista francés Alfonse Louis Constant, mejor conocido como Eliphas Lévi, quien publicó en la década de los 50 del siglo XIX sus tres principales libros: Dogme et rituel de la Haute Magie (1854) y Historie de la magie y La clef des grands mysteres, estos dos de 1859.

En lengua española el término esotérico también precedió a esoterismo y fue recogido por primera vez en 1853, en el Diccionario Nacional, de Ramón Joaquín Domínguez, aunque tardará más de un siglo para que el Diccionario de la Real Academia de la Lengua lo recoja, en 1956. Después de Éliphas Lévi, otros ocultistas que contribuyeron mucho a popularizar el término fueron los teósofos H.P. Blavatsky y A. P. Sinnett, quienes impulsaron por un tiempo el término "budismo esotérico" para referirse a la teosofía, su particular propuesta doctrinal.

Debe notarse que dichos términos (esotérico y esoterismo) no surgieron, ni en los tiempos antiguos ni en los modernos, de los discursos de los autores y practicantes religiosos aludidos por ellos, no fue una “autodesignación”, sino que más bien surgió en el nivel de sus estudiosos y críticos, diríase que en un plano académico, como bien lo señala Hanegraaff, "aplicado a posteriori aciertos desarrollos religiosos en el contexto del cristianismo temprano. En la investigación académica actual el término todavía es empleado como un constructo académico" "2. En cierto sentido podría decirse que fueron los esoterólogos (aunque no se llamaran así), sus pioneros cuando menos, los que inventaron el esoterismo como término lingüístico para aludir a un incipiente campo de estudios, y luego llegaron los esoteristas (los practicantes) para popularizarlo.

Aquí podría uno pensar en una distinción equivalente entre los estudiosos del

\footnotetext{
${ }^{1}$ Pierre Riffard, L'Ésotérisme. Qu'est-ce que l'ésotérisme? Anthologie de l'ésotérisme occidental (Paris: Éditions Robert Laffont, 1990), 65-69.

${ }^{2}$ Wouter J. Hanegraaff, Antoine Faivre, Roelof van der Broek y Jean-Pierre Brach, Dictionary of Gnosis \& Western Esotericism (Leiden: Brill, 2006), 337.
} 
gnosticismo antiguo y un escritor de literatura fantástica contemporánea, Jorge Luis Borges, cuando distinguían entre los "heresiarcas" (los autores de obra herética) y los heresiólogos, sus comentaristas. En su cuento "Tlon, Uqbar, Orbis Tertius", Borges habla de los "heresiarcas de Uqbar", uno de los cuales "había declarado que los espejos y la cópula son abominables porque multiplican el número de los hombres"3, mientras que en el último párrafo de "Tres versiones de Judas", escribe, a propósito de las tesis del ficticio teólogo sueco Nils Runeberg: "Los heresiólogos tal vez lo recordarán; agregó al concepto del Hijo, que parecía agotado, las complejidades del mal y del infortunio"4. En un caso, el heresiarca declara directamente su herejía; en el otro, el heresiólogo apenas la comenta.

Por su parte, desde el inicio, los propios esoteristas del siglo XIX se interesaron, además de escribir sus textos doctrinales, en los de tipo "histórico", que buscaban recuperar el desarrollo cronológico de su propio linaje. Así lo hicieron Eliphas Levi con su Historie de la magie y Blavatsky en The Secret Doctrine (1888), aunque con ella tal objetivo solo fue parcialmente logrado, pues no completó el volumen planeado para ello, sino que apenas quedaron algunos textos sueltos. Evidentemente libros como estos carecen de los méritos críticos necesarios de tipo lingüístico e histórico aceptados hoy por la academia, pero tienen el valor de testimoniar una incipiente "conciencia histórica" entre los propios esoteristas, que se muestran así bajo el influjo historicista romántico, conformando un nuevo tipo de esoterismo en tiempos de ciencia, democracia y modernidad.

\section{Esoterología y "estudios de esoterismo occidental"}

Primero fue lo esotérico, después el esoterismo, luego aparecería la esoterología, ya en la segunda mitad del siglo XX, sobre todo en su última década. Viene precedida por las disciplinas de estudios de las religiones, o de historia de las religiones, o de religiones comparadas (las diferencias entre estas denominaciones no siempre son claras), centradas sobre todo en la figura de Mircea Eliade, quien, junto con Carl Jung, son los representantes máximos del enfoque arquetípico de lo religioso, lo simbólico y lo psicológico, que en ellos van juntos. Conforman, junto con otras figuras como la del islamista Henry Corbin y la del estudioso de la cábala Gershom Scholem, lo que Hanegraaff ha denominado el "paradigma de Eranos", en referencia al lugar suizo donde anualmente se reunieron múltiples conferencistas a lo largo de más de medio siglo, desde principios de los 30 hasta finales de los 80 , para exponer y discutir asuntos religiosos y filosóficos ${ }^{5}$.

Visto con cierta distancia, la influencia de esta tendencia de estudio fue sobre todo teórica y metodológica, con el uso de categorías como mito, símbolo, arquetipo o

\footnotetext{
${ }^{3}$ Jorge Luis Borges, Obras completas (Buenos Aires: Emecé Editores, 1974), 431.

${ }^{4}$ Borges, Obras completas, 518.

${ }^{5}$ Steven M. Wasserstrom, Religion after Religion. Gershom Scholem, Mircea Eliade and Henry Corbin at Eranos (New Jersey: Princeton University Press, 1997).
} 
inconsciente colectivo. Por supuesto, supuso también una revisión enciclopédica del fenómeno religioso, que sin embargo, se mostró algo desdeñosa del análisis del esoterismo contemporáneo (de los siglos XIX y XX), como se muestra por ejemplo en el libro de Eliade titulado significativamente Ocultismo, brujería y modas culturales, donde aparece su ensayo "Lo oculto y el mundo moderno", en el que la capacidad analítica y erudita de Eliade aparece algo disminuida, quizá por su falta de interés en esos desarrollos religiosos tardíos (con excepción del trabajo de René Guénon). Esto explica en parte las afinidades del paradigma de Eranos con el tradicionalismo de Guénon y sus continuadores, sobre todo en el ámbito francófono, corriente en la que el esoterismo moderno (contradicción en sus términos para sus adherentes "perennialistas", para quienes todo esoterismo sería "tradicional") era fuertemente impugnado como una degeneración más de la modernidad del Kali Yuga. Tanto los de Eranos (Eliade en especial) como el tradicionalismo hacen énfasis en los aspectos hermenéuticos más que en los historicistas. Temeroso Eliade de que el historicismo en los estudios de las religiones pueda devenir en reduccionismo, escribe en su diario al respecto:

I have never affirmed the insignificance of historical situations, their usefulness for understanding religious creations. If I haven't emphasized this problem, it is precisely because it has been emphasized too much, and because what seems to me essential is thus neglected: the hermeneutic of religious creations ${ }^{6}$.

En mi opinión, más importante que el paradigma de Eranos (y su aliado tradicionalista) para la por entonces futura esoterología, fue el trabajo de la historiadora inglesa Frances Yates, en especial su obra Giordano Bruno y la tradición hermética (1964), que planteaba la existencia del hermetismo como una corriente importante pero desdeñada en la historia intelectual moderna, sobre todo en el campo de filosofía de la ciencia, pues la autora establecía una fuerte relación entre hermetismo y revolución científica $^{7}$. Con ella queda más claro el campo de acción de los inminentes estudios esoterológicos, a partir del Renacimiento y de la confluencia que ahí se dio entre neoplatonismo, cábala (cristianizada) y hermetismo, que se constituyen en las corrientes básicas (aunque no exclusivas) del esoterismo subsiguiente. Con el "paradigma Yates" el esoterismo (que ella vio más bien como hermetismo) deja de ser un término volátil e incierto, o una degeneración irracional o moderna, para ir adquiriendo un perfil histórico más preciso, susceptible de ser mapeado en sus metamorfosis históricas en los

\footnotetext{
${ }^{6}$ Citado por Arthur Versluis, "What is esoteric? Methods in the Study of Western Esotericism", Esoterica IV (2002): 1-15 [citado el 13 de abril de 2015]: disponible en http://www.esoteric.msu.edu/VolumeIV/Methods.htm. Nunca he afirmado la insignificancia de las situaciones históricas, su utilidad para la comprensión de las creaciones religiosas. Si yo no he enfatizado este problema, es precisamente porque ha sido enfatizado demasiado, y porque lo que me parece esencial es entonces dejado de lado: la hermenéutica de las creaciones religiosas.

${ }^{7}$ Hanegraaff, Esotericism and the Academy. Rejected Knowledge in Western Culture (Cambridge: Cambridge University Press, 2012), 323-334.
} 
últimos siglos en Occidente, y que se expresa, entre otras formas, en un corpus textual que conlleva escritos, imágenes y diversas artes como pintura y música.

Es en la última década del siglo pasado cuando se afianza en buen grado el campo de los estudios de lo esotérico en el mundo académico, gracias en buena medida a Antoine Faivre. Su paradigma del esoterismo como una "forma de conocer" identificable por la presencia de 6 rasgos, 4 básicos y 2 relativos, ha tenido una gran aceptación académica, vista no necesariamente como una propuesta esencialista sino más bien como un asunto heurístico, esto es, de creatividad en la lectura y la investigación.

Los cuatro rasgos básicos de lo esotérico son: a) un trasfondo de correspondencias mueve el universo, cuando se establecen relaciones entre elementos que pertenecen a órdenes distintos, con lo que se establece como forma de pensar a la analogía. b) La naturaleza se concibe como un organismo viviente, para nada es la máquina impersonal de los ilustrados materialistas. c) La imaginación, y no la razón, se concibe como la facultad humana por excelencia, vinculada con la intuición y a veces con el acceso a los arquetipos. En palabras de Faivre, "es una herramienta de conocimiento del yo, del mundo, del mito"8. d) La vivencia esotérica supone una experiencia de transmutación, en claro sentido alquímico de una metamorfosis interna del sujeto.

Los dos rasgos relativos de lo esotérico son: a) La práctica de la búsqueda de concordancias entre las diversas tradiciones religiosas a partir de similitudes estructurales, un hálito ecuménico sobre lo diverso, que suele desesperar al especialista crítico. b) Está el asunto de la transmisión de la enseñanza de una generación a la siguiente por medio de la relación maestro-discípulo a lo largo del tiempo, esto es, la autoridad del linaje y la continuidad y control de la enseñanza.

A diferencia de la perspectiva tipológica o estructural de Eranos, que trabaja lo esotérico en un contexto de estudios de religiones, en su vínculo con lo secreto, con un acceso restringido al conocimiento último e iluminador, sólo para iniciados, en otra dirección la perspectiva más historicista de Faivre "restringe " la aplicación histórica y cultural del término esoterismo, que ya no puede aplicarse así nomás a diversos contextos religiosos, a lo largo de la historia y las culturas, sino que se refiere sobre todo a un constructo intelectual europeo aplicable a partir del Renacimiento, que ve el esoterismo, no como una dimensión estructural de la religión, sino como un aspecto general de ciertas corrientes europeas, similares entre sí y vinculadas por la historia. Por eso se acuña el término "esoterismo occidental". Alude no solo a su origen sino también a su principal campo de aplicación. A partir de la confluencia, en contexto cristiano, de antiguas fuentes (neoplatónicas, herméticas, cabalistas, alquímicas) en el esoterismo renacentista, Faivre brinda un intento de periodización: una etapa formativa antigua y medieval; una de síntesis y conformación, propiamente renacentista; luego un desarrollo barroco en el siglo XVII, después un esoterismo ilustrado, seguido por uno romántico y

\footnotetext{
${ }^{8}$ Antoine Faivre, Access to Western Esotericism (New York: State University of New York Press, 1994), 13.
} 
otro del siglo XX. A estas alturas, ya hasta podría agregarse un esoterismo posmoderno. En esta lógica explicativa, el término esoterismo solo es aplicable en stricto sensu en Europa a partir del Renacimiento, y en América, solo después de la llegada de los europeos. No habría, pues, un esoterismo prehispánico, por lo que, para hablar de prácticas y discursos más o menos equivalentes en las culturas originarias, habría primero que reflexionar y quizás generar otras categorías respetuosas de sus particularidades (sobre una base histórica, antropológica y lingüística), y no aplicar un concepto occidental a secas, con base en datos parciales y descontextualizados, en un acto de colonialismo intelectual.

La propuesta heurística de Faivre no brinda solo esa útil caracterización estructural de seis rasgos de lo esotérico en tanto forma de pensamiento culturalmente delimitada, sino que además aporta una cronología de lo esotérico que favorece nuevas lecturas e interpretaciones al respecto, un conocimiento de conjunto por periodos del entramado esotérico, un seguimiento de influjos y corrientes específicas. Esto permite entender su aceptación entre muchos investigadores. De igual forma, se le han hecho muchas objeciones a este paradigma: que calza mejor para ciertas corrientes o periodos que para otros, o que es más aplicable a los períodos moderno y contemporáneo y no tanto para los medievales y antiguos, o bien objeciones que opinan lo contrario: que el esquema esoterológico de Faivre es tan general que hasta podría aplicarse a esoterismos tan lejanos como el del budismo tibetano, con lo que, de paso, el epíteto "occidental" de la etiqueta "esoterismo occidental" tiende así a verse algo disminuido. O bien, que le faltan rasgos esenciales a su caracterización, como la necesidad de una gnosis (Versluis), objeción más bien endeble pues la gnosis está contenida en el rasgo de transmutación y metamorfosis; o bien, que le sobran rasgos, o que no siempre se cumplen todos, como el lugar importante de la facultad de la imaginación, ausente en ciertos esoterismos como el de Gurdjieff (Pecotic), o en propuestas asiáticas como el Zen, el Dzogchen o Krishnamurti (asumiendo que este último pertenezca al ámbito esotérico no solo por lo histórico -sus orígenes neoteosóficos- sino por la doctrina, algo que estaría por debatirse, pues el propio K negó el carácter esotérico a su enseñanza de madurez).

Por el tiempo en que Faivre presentaba su propuesta académica de "estudios de esoterismo occidental", también lo hacía Pierre Riffard, quien en su libro L'ésotérisme establecía su propio planteamiento respecto a cómo definir el término y cómo estudiarlo, apelando a la categoría de "esoterología", a la que define como "un conocimiento sintético y teórico que puede comparar e interpretar, buscar leyes y tipos, encontrar estructuras y funciones, determinar la naturaleza y la vivencia del esoterismo en general", y entre sus objetivos están "la historia del esoterismo en general, el estudio de la idea de esoterismo, el análisis de su objeto, de su método, de su producción, de su influencia, de sus condiciones, de su lenguaje. La esoterología puede estudiarse a ella misma, estableciendo su propia historia, su metodología, su ámbito" ${ }^{\text {. }}$.

\footnotetext{
${ }^{9}$ Riffard, L'Ésotérisme, 54.

${ }^{10}$ Riffard, L'Ésotérisme, 54.
} 
Nótese que Riffard habla de un "esoterismo en general", más que de "esoterismo occidental"a la Faivre, y en esto se nota su carácter más estructuralista, de aplicación universal, por oposición a Faivre, en quien predomina una propuesta más empírica e historicista, que se va a acentuar después en el campo de estudios con Hanegraaff. A la cautela histórica de Faivre cuando revisa la dinámica esotérica en una cultura, Riffard antepone su propuesta esoterológica con una perspectiva aplicable a toda cultura, con una vocación universalista. Prueba de esto es su posterior volumen Ésotérismes d'ailleurs $^{11}$, en que aborda los "esoterismos no occidentales" con su metodología general. A partir de esto, podría uno pensar que el término esoterología es entonces distinto al de "estudios de esoterismo occidental", y esto es cierto en cuanto a algunos asuntos metodológicos o de aplicabilidad histórica, pero no lo es si lo vemos en cuanto a estudio y crítica de lo esotérico en sociedad. Después de todo, en diferente grado, en ambas perspectivas hay atención a lo empírico e histórico, lo que, como Hannegraaff ha precisado, supone del estudioso un acercamiento neutral, informado, abierto, con una dialéctica equilibrada entre lo émico y lo ético, entre lo interno y lo exterior, entre lo subjetivo y lo objetivo. El autor holandés habla incluso de una suerte de escepticismo metodológico en el investigador. Otro autor, Versluis, sin despreciar el análisis crítico, propone un empirismo empático, que no descuide los elementos hermenéuticos. En 2005, Kocku von Stuckard ha hecho una propuesta más desconstructivista, aplicando el concepto de "campo discursivo" y hablando más de lo esotérico que del esoterismo, para no sustancializar el fenómeno y verlo en interacción con otros ámbitos sociales.

Creo que ambas expresiones, esoterología y estudios de esoterismo occidental, pueden usarse en un nivel general como equivalentes, aunque a niveles más específicos (teóricos y metodológicos) haya diferencias. En términos prácticos, y no por diferencias de contenido, creo que esoterología es más útil porque es más corto, más directo, y desde el principio señala su rango académico, sin todos los supuestos implícitos de la expresión "esoterismo occidental". Ambos términos implican un campo de estudios interdisciplinarios y multidisciplinarios, sin un enfoque teórico único, aunque predomine lo empírico e histórico, evitando eso sí el peligro reduccionista, con una visión amplia de las diversas corrientes y subcorrientes del esoterismo en Europa y América a partir del Renacimiento, aisladas o en interacción entre ellas o con otros ámbitos culturales: la literatura, la música, la política, etc., todo esto tratado con empatía hermenéutica de parte del estudioso, sobre una base de escepticismo metodológico.

Si el paradigma de Eranos tenía un énfasis en lo hermenéutico, y el paradigma de Yates mostraba más bien un perfil historicista, entonces, desde una visión comparada, podría verse el paradigma de Faivre como una suerte de síntesis entre ellos dos, una especie de andrógino teórico que combina los mejores rasgos de uno y otro.

Otro punto que convendría revisar se refiere a la progresiva institucionalización académica de la esoterología, pese a sus disputas teóricas o históricas. Ya en 1965 se estableció en la Sorbona la cátedra de Historia del Esoterismo Occidental, y quien la

\footnotetext{
${ }^{11}$ Riffard, Ésotérismes d'ailleurs. Les ésotérismes non occidentaux (Paris: Éditions Robert Laffont, 1997).
} 
inauguró fue Francois Secret, un especialista en cábala cristiana. Después han surgido dos cátedras más, una en la Universidad de Amsterdam y otra en la Universidad de Exeter, Gran Bretaña, con posgrados. Las asociaciones de investigadores, las publicaciones, las revistas, los congresos, se han multiplicado en las últimas dos décadas. En cuanto a las asociaciones de estudiosos, en 2002 se creó la Association for the Study of Esotericism (ASE), y tres años después la European Society for the Study of Western Esotericism (ESSWE). Más recientemente, en 2011, se creó el Centro de Estudios sobre el Esoterismo Occidental de la Unión de Naciones Suramericanas (CEEO-UNASUR), centrado en la Universidad de Buenos Aires, con investigadores de diversos países latinoamericanos, en lenguas castellana y portuguesa. Como puede verse por los nombres de las asociaciones, es llamativo que la categoría que terminó imponiéndose académicamente es "estudios de esoterismo occidental" y no "esoterología", que funciona más en el área francófona.

\section{Bibliografía}

Borges, Jorge Luis. Obras completas. Buenos Aires: Emecé Editores, 1974.

Faivre, Antoine. Access to Western Esotericism. New York: State University of New York Press, 1994.

Hanegraaff, Wouter J., Antoine Faivre, Roelof van der Broek y Jean-Pierre Brach. Dictionary of Gnosis \& Western Esotericism. Leiden: Brill, 2006.

Hanegraaff Wouter J. Esotericism and the Academy. Rejected Knowledge in Western Culture. Cambridge: Cambridge University Press, 2012.

Riffard, Pierre. L'Ésotérisme. Qu'est-ce que l'ésotérisme? Anthologie de l'ésotérisme occidental. Paris: Éditions Robert Laffont, 1990.

Riffard, Pierre. Ésotérismes d'ailleurs. Les ésotérismes non occidentaux. Paris: Éditions Robert Laffont, 1997.

Versluis, Arthur. "What is esoteric? Methods in the Study of Western Esotericism". Esoterica IV (2002): 1-15. Disponible en http://www.esoteric.msu.edu/VolumeIV/Methods.htm

von Stuckrad, Kocku. Western Esotericism. A Brief History of Secret Knowledge. London: Equinox Publishing, 2005.

Wasserstrom, Steven M. Religion after Religion. Gershom Scholem, Mircea Eliade and Henry Corbin at Eranos. New Jersey: Princeton University Press, 1997. 